\title{
FRANCISCO RAMÍREZ VAS: PRENSA Y FILOSOFÍA MÉDICAS EN EL TERCER CUARTO DEL SIGLO XIX
}

\author{
Diego Peral Pacheco y José Luis Sánchez Álvarez
}

Universidad de Extremadura

\begin{abstract}
RESUMEN
Pretendemos rescatar del olvido a una de las firmas habituales en la prensa médica española del tercer cuarto del siglo XIX. Médico polifacético, de ideas filantrópicas, pionero del periodismo médico extremeño, higienista convencido, y reputado colaborador de diversas publicaciones nacionales. Cimentó su prestigio en una concepción moderna de la medicina, en la claridad a la hora de exponer sus principios y en la aplicación de los mismos en su trabajo diario. Buena parte de su filosofía médica quedó reflejada en la prensa médica y en la correspondencia que mantuvo con los profesionales que en ella escribían.
\end{abstract}

PALABRAS CLAVE: Prensa médica. Higiene. Escuela. Cólera.

FRANCISCO RAMÍREZ VAS: PRESS AND MEDICAL PHILOSOPHY IN THE THIRD QUARTER OF THE $19^{\mathrm{TH}}$ CENTURY

\begin{abstract}
Through present work we try to rescue of the forgetfulness to one of the habitual companies in presses medical Spanish to him of the third quarter of century XIX. Versatile doctor, of philanthropics ideas, pioneer of the frontier, hygienist medical convinced, and reputed collaborating of diverse national publications. It laid the foundations its prestige in a modern conception of the medicine, in the clarity to the hour to expose its principles and in the application of such in its daily work. Good it divides its philosophy medical was reflected in the medical press and the correspondence that maintained with the professionals who in her wrote.
\end{abstract}

KEY WORDS: Press. Hygiene. School. Cholera. Paediatrics.

\section{INTRODUCCIÓN}

Todos los cambios sociales que tienen lugar en el siglo XIX, la generalización de la enseñanza y la libertad de expresión una vez finalizado el Antiguo Régimen, favorecen el desarrollo, entre otros factores, de nuevos cauces de 
comunicación $^{1}$, siendo la prensa escrita la que inicia un período que duraría más de un siglo como único medio de comunicación entre masas ${ }^{2}$. La aparición de sociedades científicas, la celebración de reuniones y congresos, la necesidad de una formación actualizada y la inestabilidad en todos los órdenes de la sociedad española justifican la actividad editorial que emerge en este siglo $^{3}$. Los primeros estudios sobre el periodismo médico español se remontan a la misma centuria que nos sirve de marco. Al ya clásico $-\mathrm{y}$ de obligada referencia - trabajo de Méndez Álvaro ${ }^{4}$, se unen otros de esa misma época, aunque de ámbito más local ${ }^{5}$. A lo largo de la siguiente centuria, van surgiendo obras de variado carácter, pero con predominio de los estudios localistas y regionalistas ${ }^{6}$, aunque también los hay que no pierden la visión de conjunto ${ }^{7}$.

Otros autores han estudiado la prensa médica como exponente de un campo médico concreto ${ }^{8}$, o para aproximarse a determinadas realidades sociales del momento ${ }^{9}$. Los trabajos relacionados con los profesionales que publica-

1 Artola, M. (1981), La burguesía revolucionaria (1808-1874), Madrid, Alianza Universidad, pp. 332-333.

2 ARTOLA (1981), p. 325.

3 GRANJEL, L.S. (1986), La medicina española contemporánea, Salamanca, Universidad de Salamanca, p. 53.

4 MÉndez Álvaro, F. (1883), Breves apuntes para la historia del periodismo médico y farmacéutico en España, Madrid, Enrique Teodoro Impresor.

5 HaRTZENBUCh, E. (1894), Apuntes para un catálogo de periódicos madrileños desde el año 1661 hasta 1870, Madrid, Est. Tip. Sucesores de Rivadeneyra.

6 FERnÁNDEZ SANZ, J.J. (1995), Metodología, archivos y fuentes bibliográficas para el estudio de la prensa médica, Documentación de las Ciencias de la Información, 18, pp. 115142. El autor enumera una larga lista de estos trabajos de carácter localista, a la que se podrían añadir algunas más. Valgan como ejemplo CABRERA AFONSO, J.R. (1989), Noticias acerca de la prensa médico-farmacéutica canaria. En IX Congreso Nacional de Historia de la Medicina, Actas III, Zaragoza, Ayuntamiento de Zaragoza y Universidad de Zaragoza, pp. 851-864. O bien LA PARra LóPEZ, E. (1983), Médicos y medicina en la prensa de Alicante en la primera mitad del siglo XIX. En VII Congreso Nacional de Historia de la Medicina, Comunicación, Alicante, Universidad de Alicante.

7 LÓPEZ PiÑero, J.M. y Terrada, M.L. (1990), Bibliografia médica hispánica (14751950), vol. III: revistas 1736-1950, Valencia, Universidad de Valencia y CSIC.

8 Calbet Camarasa, J.M. (1970), La prensa homeopática en Cataluña, Asclepio, 22, pp. 39-48. O también CAMACHO IGLESIAS, A. (2005), El niño en la prensa médica del siglo XIX en el Distrito Universitario Hispalense, Tesis doctoral, Cádiz, Universidad de Cádiz.

9 Perdiguero, E. (2004), Niños desprotegidos. Un problema social y de salud en la prensa médica valenciana (1855-1939). En Perdiguero, E. (ed.), Salvad al niño, Valencia, Universidad de Valencia, pp. 195-218. 
ban en periódicos y revistas médicas normalmente los encontramos enmarcados en las correspondientes biografías.

Actualmente, las razones para continuar el estudio de la prensa médica son muy diversas, como vemos en algunos trabajos recientes que se reseñan, incluyendo nuevos intentos de catalogación de la misma ${ }^{10}$.

En las páginas siguientes, procederemos a analizar una pequeña parte de esta prensa médica decimonónica. Corresponde a los artículos salidos de la pluma de un autor que gozó de cierto predicamento en vida y que tienen la particularidad de ser el reflejo, no ya de su filosofía médica, sino también de su trabajo diario. Nos ayudaremos en el análisis, de la correspondencia que mantuvo con el entorno del periodismo médico, pues no en vano fue el correo la causa antecedente del periodismo científico ${ }^{11}$.

\section{EL AUTOR}

Defensor de su profesión y de los profesionales de la salud. Combativo, generoso, despiadado en su dialéctica, filántropo, inquieto, comprometido, vanidoso y por encima de todo, olvidado. Éste sería el calificativo actualmente más apropiado, entre una larga lista, que podríamos adjudicar con más rigor a nuestro protagonista, Francisco Ramírez Vas.

Nació en la localidad cántabra de Santoña en 1818, por estar allí destinado su padre, alistado en el Ejército en 1812 para combatir a las fuerzas napoleónicas. Antes de finalizar ese año, su familia regresó a Olivenza, pueblo natal de su madre, en donde había nacido su hermano mayor y en donde vendrían al mundo el resto de sus hermanos.

Destinado al sacerdocio, el cierre en 1835 de los centros de enseñanza religiosa, le empujó hacia la medicina, cuyos estudios inició en la misma Salamanca en la que estuvo más de tres años aprendiendo Filosofía y Teología. Concluyó brillantemente en Madrid en 1848, tras un amplio paréntesis de cinco años que pasó en La Habana, cumpliendo sus deberes militares como practicante del regimiento destinado al Castillo del Príncipe.

En este mismo año de 1848 se asienta en la población pacense de Olivenza como médico de la Santa Casa de Misericordia y como médico-cirujano titu-

10 FERNÁNDEZ SANZ (1995).

11 Llorente Santacatalina, S. (2005), Las revistas médicas españolas. Antecedentes y catálogo colectivo (1736-1850), Documentos de las Ciencias de la Información, vol. 28, pp. 211-256. 
lar de dicha localidad ${ }^{12}$. Desarrollará su labor en esta población hasta su muerte, que tendrá lugar en 1880.

El desempeño de su trabajo lo fundamenta en sus buenos conocimientos científicos. En su contra señalamos su carácter inflexible en lo tocante a su profesión.

De su actividad profesional se benefician no sólo los oliventinos, sino poblaciones cercanas, incluso de la vecina Portugal ${ }^{13}$.

La epidemia de cólera que en 1855 asola Olivenza dará ocasión a que Ramírez muestre su verdadera dimensión como médico y como persona. Con respecto a lo primero, pone en práctica su convencimiento sobre la contagiosidad del cólera, procurando el aislamiento de los enfermos, a la vez que critica ciertas prácticas extendidas por Europa ${ }^{14}$. Las medidas por él adoptadas

12 Se establece en Olivenza tras la firma de un acuerdo con el médico titular de la localidad, Ignacio Arviña, por el que Ramírez se hace cargo de las obligaciones de aquél a cambio de un reparto equitativo de los ingresos, según consta en el archivo de Francisco Ramírez Vas (en adelante, ARV). El acuerdo se firmó el 12 de julio de 1848. ARV, leg. 3, carpeta 18 (ARV, 3/18), tras el visto bueno del Ayuntamiento, de la Casa de Misericordia (ARV, 3/91, de fecha 16 de julio de 1848) y del Gobernador Militar de la plaza (ARV, 5/31, de 23 de agosto de 1848). El archivo de Francisco Ramírez Vas permaneció en la casa de la familia Ramírez, en Olivenza, hasta 1990, siendo trasladado entonces a Mérida, permaneciendo en manos de sus descendientes. Conserva la ordenación que le dio su dueño, que, con no ser la más adecuada, es bastante operativa. Los dos primeros legajos contienen datos familiares, en especial de su padre. En los posteriores, se almacena información agrupada por temas: sus años de estudiante, sus inicios como médico (con datos sobre la epidemia de cólera y sobre su periódico), instituciones a las que perteneció, sanidad militar, la Subdelegación de Sanidad, el caso de la ciega de Villafranca, su producción literaria no científica, parte de los artículos científi$\cos \mathrm{y}$, algo fundamental, dos legajos que contienen la correspondencia. Completa el archivo un grupo heterogéneo de documentos que incluye información sobre algunos miembros de la familia. Hay que señalar la existencia de documentos sin catalogar. Es importante la presencia de varios libros de registro, entre los que cabe destacar dos de ellos, dedicados a la contabilidad de sus actividades económicas, incluyendo todo lo referente a su actividad profesional.

13 De ello encontramos datos en los libros de registro de sus actividades, conservados en su archivo. Los mencionados libros recogen, en apartados específicos, todos sus asuntos económicos. En el relativo a la actividad médica, refleja las visitas realizadas desde 1851 hasta 1879 mediante un registro diario en el que figuran datos identificativos del paciente, su dirección, el número de visitas diarias al mismo y, por supuesto, el importe de la asistencia. Entrado $1870 \mathrm{y}$ hasta 1879 , introduce, además, el motivo de su actuación con respecto al paciente, bien sea una operación, un parto, una autopsia o un certificado. Y, lógicamente, en los casos de enfermedad, el diagnóstico de la misma, dando lugar a un registro de morbilidad extraordinariamente raro en el ámbito extrahospitalario en esa época.

14 Archivo Histórico Municipal de Olivenza, leg. 12, carpeta 1, fol. 201 (AHMO 12/1201). En la sesión de la corporación municipal celebrada el 25 de julio, en la que se acordaba la contratación de un nuevo médico, por enfermedad del otro titular y Subdelegado médico, 
con respecto a la población en general como en el hospital de coléricos limitarán a un centenar las defunciones a causa de la epidemia ${ }^{15}$. En cuanto a los acuartelamientos militares de la población, el número de víctimas se reducirá a dos ${ }^{16}$. Referente a lo segundo, se produce un hecho que a la postre ha eclipsado la valía de Ramírez como médico para algunos de los pocos historiadores que se han ocupado de él, quedando para la posteridad exclusivamente como un filántropo ${ }^{17}$. El asunto en cuestión es el ofrecimiento de Ramírez para asistir de forma gratuita a los pobres mientras durara la epidemia de cólera. Y si eso no bastaba, renuncia a un tercio de su sueldo como médico de la Santa Casa de Misericordia para que a la Institución le sea menos gravosa la asistencia que presta a los contagiados ${ }^{18}$. El gesto es ya de por sí loable, pero mucho más en las circunstancias en que se produjo. Los dos primeros casos de cólera, con desenlace fatal, se produjeron en la sala de cirugía de la Casa de Misericordia, inhibiéndose el cirujano (Victoriano de Parra) y siendo Ramírez el que da la voz de alarma. La consecuencia de este hecho no pudo ser más inesperada ni desmoralizadora para un profesional de la medicina. Lo vemos en las propias palabras de las autoridades locales ${ }^{19}$ :

Victoriano de Parra, se determinaba el cierre de las escuelas a causa del cólera. Entre las medidas adoptadas llama la atención la que sigue: «A invitación de los facultativos se acordó que los vecinos hagan hogueras de romero á las puertas de sus casas y que se introduzca ganado vacuno por las noches en la población». Las hogueras de romero era una medida bastante extendida, y contra ella manifiesta su desacuerdo Ramírez.

15 Valgan como comparación los datos relativos al cólera del año anterior en la vecina Badajoz, que duplicando la población de Olivenza, multiplicó por ocho el número de víctimas. Memoria de la Junta Municipal de Sanidad de Badajoz, 1854, Badajoz, pp. 3-7

16 Ramírez realiza una tosca estadística del desarrollo de la epidemia con la anotación nominal diaria de los enfermos y el desenlace final de cada uno: curación o fallecimiento. ARV, 4/33.

17 Vallecillo Teodoro, M.A. (1999), Olivenza en su historia, Badajoz, Indugrafic, p. 368. En similares términos se expresan otros autores de obras menores.

18 Ofrecimiento hecho mediante carta de fecha 22 de julio de 1855. Archivo de la Santa Casa de Misericordia de Olivenza (ASCMO), 153/2807-6. Se le comunica la aceptación al día siguiente, expresándose el Proveedor en los siguientes términos: «Con satisfacción recibió esta Junta en sesión de ayer el oficio que v. me remitió, brotando en él filantrópicos sentimientos, de los que se halla v. adornado; y maxime prestando sus servicios espontáneos y gratuitos en el Hospital provisional, situado en el cuartel de la Panadería, y además ceder en beneficio de este Establecimiento la tercera parte de sus dotaciones mientras duren las tristes circunstancias actuales...». ARV, 4/10.

19 ARV, 4/26. Aunque en el escrito se mencionan las salas de medicina como el origen de la epidemia, en el informe remitido por el propio Ramírez al Gobierno Civil, bajo el título de Ocurrencias del cólera (ARV, 4/24), se nos relatan los hechos tal y como hemos expresado. 
D. Vicente Carvallo, Alcalde Segundo Constitucional de esta villa,

Certifico: Que a consecuencia de haber sido el Licenciado en Medicina y cirugía D. Francisco Ramírez Vas el que franca y lealmente declaró la aparición de los primeros casos de cólera en las salas de medicina, que dignamente visita en el hospital de Caridad de esta villa, se hizo blanco inmerecido de calumnias y denigrantes suposiciones, llegando a tacharlo la opinión pública hasta de envenenador; pues se decía que daba unos polvos con los que mataba á los enfermos, para hacer creer que era cierta la existencia del cólera: que esto lo hacía porque declarándose la epidemia, le iban a dar una cruz y cinco duros diarios (...) llegando á predisponer los ánimos de tal modo en contra del citado profesor, que yo mismo le aconsegé no saliese de noche de casa sin ir acompañado. A pesar de tantas calumnias y de haber sufrido varios insultos en una plaza pública delante de muchas personas, el Sr. D. Francisco Ramírez se condujo con el mayor comedimiento, no queriendo proceder contra sus detractores (...) con cuya noble y delicada conducta vencio a sus enemigos y se granjeó el cariño y confianza de todo el pueblo...

A pesar de todo, no renuncia a su cometido, llegando incluso a manifestar síntomas de haber contraído la enfermedad ${ }^{20}$. Una vez concluida la epidemia, recibe numerosas muestras de agradecimiento de diversas autoridades civiles y militares, siendo de especial relevancia la del Gobernador Civil de la provincia $^{21}$. Como colofón a la larga nómina de reconocimientos, a finales de 1855 y durante 1856, le serán concedidas varias distinciones: la Real Orden de Carlos III ${ }^{22}$, la Cruz de Epidemias y la Cruz de la Orden Civil de Beneficencia, estas dos últimas en el verano de 1856.

Como ya se ha dado a entender al mencionar el hospital militar de coléricos, la asistencia de las tropas destacadas en Olivenza solía estar a cargo de los médicos civiles de la población. Recordemos aquí que Olivenza perteneció a Portugal hasta 1801, en que, merced a la Guerra de las Naranjas, pasó a la Corona española. Hasta entonces la Santa Casa de Misericordia, fundada en 1501 , se había ocupado de asistir a los militares. Aunque el cambio de nacionalidad no supuso ninguna alteración sustancial en el cometido ni en la es-

20 ARV, 4/21. Certificación de haber padecido cólera, expedido por el doctor Gómez. También carpeta 22, id. por el doctor Ramos. Ambos facultativos le diagnosticaron la enfermedad la noche del 8 de agosto. Igualmente se reconoce en diversos documentos como el de la carpeta 28, correspondiendo la certificación al Ayuntamiento de Olivenza.

21 BOP n. $^{\circ} 11$, de 25 de enero de 1856, p. 1. En este Boletín Oficial de la Provincia de Badajoz se da cuenta de diversos agradecimientos a instituciones y personas. Y entre los escasos médicos que figuran en ella, encontramos a Ramírez.

22 ARV, 13/121. El 27 de noviembre de 1855, mediante oficio firmado por Pedro Felipe Monlau, se le comunica la mencionada distinción. 
tructura de la Institución ${ }^{23}$, sí apreciamos algunas novedades, consecuencia de las dificultades para establecer en la población una asistencia médica que tuviera continuidad ${ }^{24}$. En 1822 se produce un hecho insólito que origina un grave enfrentamiento entre el Ayuntamiento y el Gobernador Militar de la plaza, motivado por la imposición por parte del estamento castrense del cirujano de Coraceros como cirujano de la localidad ${ }^{25}$. Esta medida suponía en la práctica que la población civil sería asistida por militares, justo lo contrario de lo que siempre había ocurrido. Con respecto a la Santa Casa, otra medida tomada en 1841 viene a trastocar, sobre el papel, su normal funcionamiento: los militares serán asistidos por militares ${ }^{26}$. Lo cierto es que en ningún momento volveremos a ver a personal militar asistiendo a civiles y en muy pocas ocasiones, y de corta duración cuando se producen, veremos a las tropas asistidas por la sanidad castrense ${ }^{27}$. La asistencia médica a los militares estará casi siempre en manos de los médicos civiles, pero para cumplir en lo posible con la Real Orden de 1841, se procederá al nombramiento de médicos militares honora-

23 Rodríguez Mateos, M.V. (2003), Los hospitales de Extremadura 1492-1700, Cáceres, Consejería de Sanidad y Consumo, Junta de Extremadura, p. 338.

24 Desde la primera convocatoria de plazas de médico en la Olivenza española (Archivo Histórico Municipal de Olivenza, Libro de actas, 7/1-82), vemos continuas desavenencias entre el municipio y sus médicos y cirujanos, fundamentadas en ocasiones por la falta de fondos en las arcas locales.

25 Archivo Histórico Municipal de Olivenza (AHMO), 8/1-256, con fecha 6 de febrero de 1822. No se le dará licencia para ejercer hasta el 17 de abril siguiente (AHMO, 8/1-271).

26 Una Real Orden de 5 de septiembre de 1841 dispone «que los militares enfermos que ingresen en hospitales civiles sean asistidos por profesores Castrenses, si los hubiese en la población». La misma, dice más adelante en su punto cuarto, «que se evite, en cuanto sea posible, el nombramiento de facultativos para hospitales civiles, en atención á que el sueldo ó gratificación que se les señala es un verdadero gravámen al presupuesto de este ministerio».

27 Desde 1842 hay referencias a la asistencia de la guarnición militar de Olivenza por parte de los médicos civiles de la localidad. El 21 de marzo 1868 se suprime la plaza de médico civil, según comunicación de la Jefatura de Sanidad de Andalucía en el mismo sentido, y que nos aporta más información: «cumpliendo lo prevenido en el artículo $3^{\circ}$ de la Real orden de 13 de Febrero próximo pasado referente á hacer las reducciones que las atenciones del servicio permitan en el personal de Profesores civiles empleados en algunos de los hospitales militares, la Reyna (q. D. g.) se ha servido resolver lo siguiente. $=1^{\circ}$ : se suprimen los servicios que en la actualidad se desempeñan en los hospitales militares que se indican en la adjunta relación $n^{\circ} 1$, los ocho profesores civiles que en la misma se espresan (...). Y hallándose incluidos en la relación $\mathrm{n}^{\mathrm{o}} 1$ que se cita los Médicos auxiliares de los Hospitales de Olivenza, Cáceres y Tarifa (...), lo traslado á V. S. para su conocimiento noticia de los interesados y á fin de que disponga sean dados de baja por fin del presente mes =». 
rios en las personas de los profesionales locales. El término «honorario» implicaba el no cobrar sueldo, aunque en ocasiones percibían gratificaciones.

De esta manera, a partir de 1848 Ramírez aparece por primera vez como médico militar honorario, sin sueldo ${ }^{28}$. A partir de 1862 , según señala en su libro de registro de haberes, y hasta 1868, año en que se suprime la plaza de Olivenza, Ramírez percibe de forma regular un sueldo como médico militar, a razón de 295 reales mensuales.

Finalizamos estas notas biográficas mencionando otros cargos desempeñados por Ramírez a lo largo de su vida profesional: forense ${ }^{29}$ (1862), Subdelegado de $\operatorname{Sanidad}^{30}$ (1871) e higienista (hasta 1873, sin conocerse el año de nombramiento ${ }^{31}$. Sobre la concesión del título de higienista debió de influir bastante el interés que se tomó por este campo y que plasmó en diversos trabajos. Estos y otros más le abrirían las puertas de diversas instituciones científicas, entre las que destacamos las Academias médicas de Sevilla ${ }^{32}$ (desde 1855), Lisboa ${ }^{33}$ (1855), Madrid ${ }^{34}$ (1860) y Badajoz ${ }^{35}$ (1872), y el Instituto Médico Valenciano ${ }^{36}$ (1854), en cuyo Boletín escribió con asiduidad.

28 ARV, 5/31, según se le comunica mediante oficio de fecha 23 de agosto de 1848.

29 La Ley de Sanidad de 28 de noviembre de 1855, en su artículo 95, sirve de base para organizar el servicio forense. Mediante el Decreto de 13 de mayo de 1862, que se fundamentaba en el mencionado artículo, se creaba un Cuerpo de Facultativos adscritos de forma permanente a los jueces. La entrada en vigor de dicho Decreto en octubre de ese año hace definitivamente posible la aparición de la figura del Médico Forense. En el mismo Decreto se disponía que cada juzgado tuviese su Médico Forense. En esta orden de cosas el Ministro Togado Honorario del Tribunal de Cuentas del Reino, transmite el nombramiento y título de Forense, efectuado el 13 de agosto de 1862, a Francisco Ramírez el 10 de octubre siguiente (ARV, 3/44).

30 ARV, 3/46. Nombramiento de 4 de noviembre de 1871.

31 ARV, 3/48. El documento del que disponemos es la comunicación, de fecha 12 de diciembre de 1877, del Gobierno Civil de Badajoz aceptando la renuncia de Ramírez al cargo de higienista.

32 ARV, 4/47. Mediante oficio de 4 de abril de 1855, se le comunica la admisión en dicha Academia.

33 ARV, 4/39. La Sociedade da Sciencias Medicas de Lisboa le comunica, con fecha 4 de marzo de 1855, la concesión del diploma de socio tras la presentación de la memoria «Importancia da Hygiene», que posteriormente será publicada en el Boletín de la sociedad lisboeta.

34 ARV, 4/48. Comunicación de la admisión como socio corresponsal, de fecha 27 de febrero de 1860 .

35 El 16 de noviembre de 1871, Benito Crespo, primer presidente de la Academia pacense, que iniciaría su trayectoria en 1872 , invita personalmente a Ramírez para que forme parte de la institución. ARV, 4/50.

36 El 19 de diciembre de 1854, es admitido como socio corresponsal. ARV, 13/9. 
A mediados de siglo, Ramírez inició su actividad como colaborador con diferentes publicaciones médicas, creando incluso su propio periódico médico. Precisamente de la actividad literaria de Ramírez trataremos en estas páginas, o de parte de ella, puesto que de su labor como autor de dramas y composiciones poéticas - algo en lo que tuvo mucho que ver su amistad con el célebre dramaturgo Antonio García Gutiérrez, allá en $\mathrm{Cuba}^{37}$-, no trataremos aquí. Más exactamente, lo haremos de su relación con el mundo de las publicaciones periódicas médicas ${ }^{38}$. Para ello nos apoyaremos en dos pilares: las publicaciones y las relaciones epistolares que Ramírez mantuvo con los artífices de las publicaciones.

Los trabajos escritos de Ramírez tratan temas variados. Junto a artículos de escaso relieve encontramos otros realmente atractivos, por cuanto son un reflejo de la medicina de la época, de sus teorías y tendencias, y de la confrontación entre distintas corrientes. Una buena muestra de todo ello la encontramos en el periódico que él mismo fundó y dirigió: El Estandarte Médico.

\section{LOS TRABAJOS PUBLICADOS}

Ramírez publicó en diferentes medios escritos, generalmente españoles ${ }^{39}$;

37 Según podemos leer en el periódico elvense $A$ voz do Alemtejo, números 50 y 51 de 1860: «E cinco annos permaneceu na Habana como praticante de um regimento, tendo amizade o distincto poeta D. Antonio Garcia Guterres. Affeiçoado tambem ao commercio das $\mathrm{Mu}-$ sas fez algunas composiçoes para o periodico, em que este escrevia, e publicou o romance "Os dois rivaes" no jornal dirigido por D. Pascoal Rego». Antonio García Gutiérrez, nacido en Chiclana de la Frontera en 1813, fue una de las figuras más destacadas del romanticismo español. Su poesía no alcanza la calidad de sus dramas en verso, que lo catapultarán a la fama a edades tempranas. En su producción dramática destacan títulos como El trovador y Simón Bocanegra. Ambas obras serán con posterioridad las que inspirarán los respectivos libretos de las conocidas óperas de Verdi Il Trovatore y Simon Boccanegra. Su popularidad, amén de diversas distinciones, le hará alcanzar elevados puestos: Comisario-interventor de la Deuda española en Londres, miembro de la Real Academia Española, Cónsul de España en Bayona y en Génova, y director del Museo Arqueológico Nacional. Curiosamente, García Gutiérrez inició los estudios de Medicina, abandonándolos por su pasión por la literatura.

38 También colaboró con otras de tipo cultural, como El Pasatiempo, de Olivenza, o El Iris, de Badajoz, según Pulido Cordero, M. y Nogales Flores, T. (1989), Publicaciones periódicas extremeñas 1808-1988, Badajoz, Diputación Provincial, pp. 178 y 159.

39 Ovilo Otero, M. (1859), Manual de biografia y de bibliografia de los escritores españoles del siglo XIX, París, Imprenta de Rublot, tomo I., pp. 156-157. A los periódicos que menciona el autor habrá que añadirle alguno más, como podemos ver en el presente trabajo. 
destacando inicialmente La Crónica de los Hospitales y siendo el Boletín del Instituto Médico Valenciano el que más trabajos atesora ${ }^{40}$.

Básicamente podríamos hablar de los de contenido corporativista y de los de tema científico. Entre los del primer grupo, destaca el publicado en 1854 con motivo de la muerte en ese año de un farmacéutico de Almendralejo durante la epidemia de cólera. Bajo un extenso y prometedor título ${ }^{41}$, se esconde una descarnada crítica a los poderes públicos por el tratamiento dado a los sanitarios durante la presente epidemia de cólera. Viene a ejemplarizarla en el trato recibido por la familia de Antonio Marcello, el joven boticario fallecido en Almendralejo en cumplimiento de su deber durante la citada epidemia. Entresacamos un párrafo clarificador, muestra también de la fina ironía que posee su autor ${ }^{42}$ :

Al publicarse en la 'Gaceta' los nombres de los que han huido y de los que permanecieron firmes en sus puestos en Almendralejo, no se hace mención del malogrado farmacéutico Marcello; pero en cambio se condecora á los particulares con las cruces de Carlos III y de Isabel la Católica: es verdad que también se manda que á los facultativos titulares se les den... las gracias!!

El núcleo de los trabajos de esta índole lo encontramos en el debate originado en torno a la creación de una Ley de Sanidad que se hacía necesaria, lo que se denominaba en la prensa de entonces «Proyecto de arreglo de los partidos», o también «Asociación Médica». Estos trabajos conforman buena parte de las páginas del periódico que va a ver la luz en Olivenza.

\section{El NACIMIENTO DE LA PRENSA MÉDICA EXTREMEÑA: EL ESTANDARTE MÉDICO}

Este ambiente convulso, perfectamente perceptible en la prensa especializada de entonces, es el caldo de cultivo para nuevas publicaciones cuya finalidad primordial es el intentar dar un impulso definitivo a una ley que satisfaga las expectativas de las clases sanitarias. La sorpresiva abolición del decreto de abril de 1854, que tantas esperanzas había despertado entre éstas, encrespó

40 Todos los trabajos publicados en él se encuentran relacionados en el índice del Boletín, en http://hicido.uv.es/IMV/IMV/index.html (consultado el 9 de marzo de 2011).

41 RAMírez VAS, F. (1854a), Reflexiones acerca de los importantísimos servicios que las clases médico-farmacéuticas han prestado en todos los tiempos, y principalmente en la actualidad, y de la indiferencia con que son atendidas, La Crónica de los Hospitales, pp. 629-634.

42 RAMíreZ VAS (1854a), pp. 633-634. 
aún más los ánimos. Mirando el análisis numérico que Méndez Álvaro hace de la aparición de publicaciones médicas durante el siglo XIX, salta a la vista, y él mismo lo hace notar, que el alumbramiento de éstas aumenta en torno a las fechas de la aparición de la Ley de Sanidad de $1855^{43}$. Otra causa de malestar para los sanitarios era la situación creada con motivo de la mencionada epidemia de cólera. Esta epidemia actuará como uno de los factores precipitantes de la aparición de la ansiada Ley de Sanidad ${ }^{44}$. Parece claro que Francisco Ramírez, habiendo dado muestras de sus inquietudes gremiales, como acabamos de ver, pudiera ser un candidato a iniciar una de estas publicaciones. En su contra jugaba el hecho de encontrarse en una localidad pequeña y periférica. Aún así juzgó pertinente lanzarse a la aventura editorial, creando en enero de 1855 El Estandarte Médico, periódico reseñado por el mismo Méndez Álvaro 45 y citado por autores posteriores ${ }^{46}$. Aunque no entraremos en pormenores de la publicación, sí dejamos constancia aquí de estar ante el primer periódico médico extremeño ${ }^{47}$. El siguiente llegaría tres décadas después.

La vida de la publicación sería muy corta, tan sólo nueve números, dejando de publicarse a finales de marzo de 1855. Apenas contó con artículos de carácter científico, abundando en los llamados «filosóficos», en los que el director, esto es, Francisco Ramírez, expone su parecer sobre determinadas cuestiones de actualidad. Fundamentalmente trata en diversos números el «proyecto de arreglo de los partidos», criticando duramente una serie de puntos, lo que dará lugar a la respuesta de uno de sus suscriptores y, a la vez, uno de los autores de dicha propuesta, Anastasio García López ${ }^{48}$. Tampoco se salvan de sus críticas los médicos dedicados a la política, como deja patente

43 RiErA, J. (ed. introducción e índices ) (1978), Francisco Méndez Alvaro. Historia del Periodismo Médico y Farmacéutico en España. En Acta Histórico-Médica Vallisoletana, vol. VIII, Valladolid, Universidad de Valladolid, p. 27.

44 Granjel, L.S. (1974), El ejercicio médico, Salamanca, Universidad de Salamanca, p. 112.

45 MÉndez Álvaro (1883), p. 79.

46 Pulido Cordero, M. y Nogales Flores, T. (1989), Publicaciones periódicas extremeñas, (1808-1988), Badajoz, Diputación de Badajoz, p. 143.

47 Regatero Bote, A. (2003), La homeopatía: su nacimiento en Badajoz, Revista de Estudios Extremeños, LIX (1), pp. 449-452. En el presente artículo, el autor cita, al igual que Méndez Álvaro y que Pulido y Nogales, un boletín de Homeopatía, publicado por el doctor Rino en 1840 en Badajoz. Al tratar exclusivamente esta materia, no lo consideramos un auténtico periódico médico.

48 Médico conquense, destacado hidrologista y homeópata. Su dilatada trayectoria es estudiada, entre otras, en la obra de ALBARRACín TEulón, A. (1989), Conferencias sobre cosmología, antropología y sociología bajo el criterio espiritualista científico, Asclepio, 41 (2), pp. 87-102. 
en uno de los números de su publicación ${ }^{49}$. Este artículo, entre otros motivos, originó una respuesta de El Siglo Médico, en su número 59, pidiendo paciencia a los médicos, lo que a su vez provocó la de Ramírez, molesto con «el citado periódico que siempre toma con calma las cuestiones de interés profesional» ${ }^{50}$.

Otros de sus artículos «filosóficos» tratan temas candentes del momento y los analizaremos en otro contexto para su mejor entendimiento.

\section{LOS GRANDES DEBATES DE LA MEDICINA DE MEDIADOS DEL XIX}

La medicina europea de inicios del siglo XIX necesitaba dotarse de rigor. En 1801 Bichat sentencia que «la Medicina ha sido rechazada durante mucho tiempo del seno de las ciencias exactas». Y así era. Salvo en los casos de las denominadas «patologías externas», todo eran conjeturas ${ }^{51}$. En esta transición de siglo, la medicina francesa recurrió al empirismo y al sensualismo de tradición hipocrática y aplicó el riguroso método analítico. A pesar de la aparición del método anatomoclínico, los médicos franceses siguieron recurriendo, en mayor o menor medida, al vitalismo para explicar el origen de la enferme$\mathrm{dad}^{52}$. En este marco se mueven las teorías de los más relevantes médicos del momento: Broussais, Pinel, Bichat, Brown y otros. La aparición de la fisiología experimental de Magendie vino a poner luz en este bosque de teorías y sistemas, aunque no faltarán nombres de relieve, como el destacado clínico Trousseau, que despreciarán el análisis y el microscopio.

Por lo que a España se refiere, el proverbial retraso en el que la pervivencia del absolutismo del Antiguo Régimen había sumido a nuestra medicina nos hace ir a remolque de la francesa, pero siempre con un notable desfase. Curiosamente tengan algo que ver en ello algunos de nuestros médicos más sonados de la época ${ }^{53}$.

49 Ramírez VAs, F. (1855a), ¿Qué hacen los diputados médicos?, El Estandarte Médico, 3, p. 37.

50 Ramírez VAS, F. (1855b), Cuatro palabras a la prensa en general y al Siglo Médico en particular, El Estandarte Médico, 7, p. 97.

51 Laín Entralgo, P. (1990), Historia de la Medicina. Barcelona, Salvat, p. 426.

52 Arquiola, E. (1992), La formulación de una teoría general de la enfermedad en Francia en el tránsito del siglo XVIII al XIX, Dynamis, 12, p. 189-208.

53 En 1859 aparece Defensa de Hipócrates, de las escuelas hipocráticas y del vitalismo. Publicado por la Real Academia de Medicina de Madrid, la obra está integrada por los dife- 
En el primer número de El Estandarte Médico, Francisco Ramírez, «para inaugurar dignamente sus tareas» — afirma en la primera página - entra en el debate existente en la medicina del momento:

(...) de la misma manera que en las escuelas filosóficas la exageración del espiritualismo condujo al materialismo más grosero y repugnante; en medicina el arqueismo de van-Helmont produjo el mecanismo de Boerhave, el humorismo engendró el solidismo, y nótase la misma lucha, sin que se pueda presentir el triunfo, entre la escuela organicista de París y la vitalista de Montpellier. Las doctrinas solidistas, aunque no exentas de trascendentales errores, serán siempre acreedoras a nuestra gratitud (...) La inauguración en nuestro siglo del solidismo, apellidado después por Broussais medicina fisiológica, ha dado el ser a la anatomía topográfica, tan necesaria para el estudio de los efectos quirúrgicos (...)

Como no podía menos de suceder, el esclusivismo sistematico e insostenible del solidismo (...) relegando a un olvido injusto al antiguo humorismo (...) debía producir (...) nuevos estudios y multiplicadas observaciones químicas y microscópicas que declaren la parte de verdad que encerraban uno y otro sistema ${ }^{54}$.

El autor refleja en el artículo la pugna de los que sostienen que el origen de la enfermedad radica en la alteración de los órganos («solidistas») y los que se siguen aferrando a las teorías galénicas («humoristas»). Desde finales del siglo XVIII, las teorías solidistas, en sus distintas variantes, habían ganado terreno. No obstante, un solidista como Bichat ya había enunciado que si la causa de la enfermedad asienta en los sólidos, la causa pueden ser los sólidos o los fluidos, por lo que no puede aceptarse un solidismo o un humorismo puro ${ }^{55}$.

Pocos años después, Ramírez volverá sobre el mismo asunto en las páginas del Boletín del Instituto Médico Valenciano ${ }^{56}$ :

Cualesquiera que hayan sido las doctrinas médicas, se las ha visto siempre girando en el mismo círculo vicioso en pos de la verdad absoluta. Se ha visto en efecto a la filosofía médica proclamar el vitalismo, abrazar después el humorismo, y echarse últimamente en brazos del solidismo para volver a empezar de nuevo en el mismo punto de partida, aunque muchas veces con nombres distintos y ligeras modificaciones esenciales. Y es que al desplomarse un sistema á impulso de sus

rentes discursos que en la mencionada Academia pronunciaron en defensa de la medicina hipocrática académicos como Santero, Méndez Álvaro o Nieto Serrano.

54 RAMírez VAS, F. (1855c), Ligero bosquejo del estado actual de la medicina, El Estandarte Médico, 1, pp. 2-4.

55 ARQuiOla (1992), p. 197.

56 RAMírez VAS, F. (1861), ¿Existen las enfermedades de los líquidos?, Boletín del Instituto Médico Valenciano, 7, p. 448. 
exageraciones y de sus absurdos, el que le sucede, lejos de utilizar las verdades descubiertas, se empeña en fundar con principios diametralmente opuestos, una nueva escuela (...).

Decir que los fluidos no sufren ni son molestados en su acción molecular, es negarse á la evidencia (...) De lo dicho se desprende toda la importancia que tiene la patología humoral y su valor semiológico tan lastimosamente olvidado, y sin cuyo examen sería en algunos casos difícil y en otras imposible el diagnóstico de la enfermedad.

Aunque defiende expresamente el «humorismo» en el párrafo que acabamos de ver, no cabe interpretarlo como tal, puesto que no está hablando del origen de la enfermedad que asienta en una alteración de los líquidos, sino en las alteraciones de los líquidos, cuyo estudio nos puede ayudar en el diagnóstico de la enfermedad. Ramírez parece estar muy al tanto de lo que ocurre en la vecina Francia y sus progresos en la medicina fisiológica ${ }^{57}$. Pero no acaba de ser tajante en sus aseveraciones y romper definitivamente con las tendencias que ha criticado con anterioridad, algo que sí haría años después Bernard ${ }^{58}$ :

La medicina experimental (...) no será vitalista, ni animista, ni organicista, ni solidista, ni humoral, será simplemente la ciencia que procura remontarse a las causas próximas de los fenómenos de la vida, en el estado sano y en el morboso.

Dentro de esta controversia sobre el origen de la enfermedad, sobresale por su actualidad el tema de la contagiosidad de algunas enfermedades. El concepto de contagiosidad es muy antiguo, siendo la concepción moderna del término atribuible a Fracastoro, con lo que nos remontamos a la primera mitad del siglo XVI. El creciente intercambio de materias primas y de manufacturas a finales del XVIII implicaba un mayor riesgo de importación de enfermedades epidémicas, siempre desde el punto de vista de la teoría miasmática, defendida por los contagionistas, que situaba el origen de estas enfermedades en los efluvios procedentes de la descomposición de la materia orgánica, en la que tenían gran influencia las condiciones atmosféricas. Estos miasmas eran productos volátiles $\mathrm{y}$, en consecuencia, eran transportados por el aire. Las medidas profilácticas de los contagionistas pasaban por las cuarentenas en lazaretos, los cordones sanitarios y las fumigaciones. Los anticontagionistas,

57 Tenemos constancia de suscripciones de Ramírez a diversas publicaciones francesas como Journal de Médicine et de Chirurgie, Gazette des Hospitaux y Suplément á l'annuaire de thérapeutique, de los que se conservan diversos ejemplares en su biblioteca.

58 IZQUIERDO, J.J. (1994), Claude Bernard. Introducción al estudio de la medicina experimental, Madrid, Dirección General de Publicaciones, Facultad de Medicina, UNAM, p. 402. 
más que un discurso coherente sobre el origen de las epidemias, aprovechaban los puntos débiles de los contagionistas para rebatir sus teorías. Así lo manifiesta el químico francés Raspail ${ }^{59}:$ ¿de qué sirven las cuarentenas y cordones sanitarios si la enfermedad se transmite por el aire?

El principal problema de los contagionistas era no poder aislar al agente causante de la enfermedad, con lo que no podían demostrar el origen de la enfermedad. Por otro lado, esta circunstancia facultaba la aparición de múltiples variantes dentro de la teoría contagionista. Esta falta de unidad reforzaba las teorías anticontagionistas. A pesar de que Acerbi, en 1822, y Henle, en 1840, habían mostrado su convencimiento sobre la contagiosidad del cólera ${ }^{60}$, las tesis anticontagionistas poseían más adeptos.

En 1854 Pettenkofer, tras estudiar la epidemia de cólera de Munich, elaboró una nueva teoría, atribuyendo al suelo el origen de la enfermedad. Su Bondentheorie sería publicada al año siguiente y tuvo tal influencia que ni el descubrimiento del germen por parte de Koch en 1883 hizo cambiar de opinión a sus partidarios ${ }^{61}$.

Existían otras teorías científicas, como la infeccionista, propuesta por Broussais, defendiendo que el origen de las enfermedades era una infección secundaria a la irritación de los intestinos ${ }^{62}$.

La repercusión de las medidas propuestas por los contagionistas en caso de epidemia tenía una influencia negativa para el comercio. Esta situación, que afectaba más a los países industrializados, acabó por convertir el debate de la contagiosidad en un asunto más político que sanitario. Países como Gran Bretaña y los del norte europeo despreciaban las cuarentenas, por creerlas inútiles; pero, sobre todo, por la negativa repercusión sobre su comercio. Enfrente, los países mediterráneos, defendiendo las medidas ya enunciadas ${ }^{63}$. Las suce-

59 Risques, A. y CARlado, A.M. (1854), Conselhos hygiénicos, preservativos, e curativos para a Cholera, segundo os principios do Sabio F. V. Raspail e doutrinas expendidas na Revista Philosophica offerecidas ao Povo Portuguez por..., Manuscrito remitido por el impresor a Francisco Ramírez Vas, p. 6.

60 LAÍN ENTRALGO (1990), p. 400-402.

61 Lederman D.W. (2003), A propósito del cólera: Max von Pettenkofer y su Experimentum Crucis, Revista Chilena de Infectología, 20, pp. 84-85.

62 Bonastra Tolos, J. (2000), Innovaciones y continuismo en las concepciones sobre el contagio y las cuarentenas en la España del siglo XIX. Reflexiones acerca del problema sanitario, económico y social, Scripta Nova. Revista electrónica de Geografía y Ciencias Sociales, 69 (35), pp. 1-7.

63 Mateos JimÉneZ, J.B. (2005), Actas de las conferencias sanitarias internacionales (1851-1938), Revista Española de Salud Pública, 79 (3), p. 340. 
sivas conferencias sanitarias internacionales convocadas a partir de 1851 con el fin de unificar criterios de lucha contra las epidemias acabaron por convertirse en el escenario de la lucha de intereses comerciales, en el que se buscaban siempre las medidas menos lesivas para los países más desarrollados ${ }^{64}$. Incluso en países mediterráneos como España, no faltarán voces que se alcen contra las medidas ejercidas contra la libre circulación del comercio ${ }^{65}$.

En este contexto, Ramírez escribe en 1854: «¿Debe aconsejarse el aislamiento de los coléricos y la incomunicación completa de los pueblos contagiados?» ${ }^{66}$. El artículo en cuestión de Ramírez nos parece doblemente interesante. Por un lado, porque en él expone sus propios razonamientos, en contraposición a las teorías más extendidas. Por otro, porque en él encontramos los fundamentos de su actuación durante la epidemia que se desencadenará en Olivenza unos meses después. Para ilustrar lo primero recurrimos a citas textuales, comenzando por la polémica de los cordones sanitarios, «... por su influencia más o menos directa en la paralización del comercio y de la industria... ${ }^{67}$, añadiendo unas líneas más abajo, que el aislamiento es la $« \ldots$. única profilaxis para la epidemia...». Más adelante, sobre la etiología y el contagio de la enfermedad, expresa lo siguiente:

(...) el intrincado problema de la etiologia colérica (...) se ha tratado de oscurecer y desfigurar, especialmente en los países comerciales, que son los mas interesados en que la verdad no brille con todo su esplendor (...) Que el cólera es importable, y que se comunica por el contacto con las personas que lo padecen ó con los efectos contagiables que de ellos proceden, nos lo está patentizando no solo los casos aislados y bien comprobados de trasmisión directa, sino tambien la marcha que en su aparicion ha seguido la epidemia...

64 MATEOS JiMÉNEZ (2005), p. 343.

65 FERnÁNDEZ DE CASTRO, M. (1879), Las cuarentenas: posibilidad de suprimir las de observación sin daño de la salubridad pública y con ventaja de la navegación y del comercio, por..., Madrid, Impr. de Fontanet, p. 10. Este ingeniero de minas se apoya en las opiniones que le son favorables a sus intereses, alegando algunas dudas de Monlau sobre que una determinada enfermedad sea siempre contagiosa, o la negación de contagiosidad que Tardieu otorga al cólera y a la fiebre amarilla.

66 RAmírez VAS, F. (1854b), ¿Debe aconsejarse el aislamiento de los coléricos y la incomunicación completa de los pueblos contagiados?, La Crónica de los Hospitales, pp. 555-556.

67 RAMÍREZ VAS (1854b), p. 556. 
En la página siguiente repite claramente su convicción:

(...) este azote del género humano es importable, y que no va a ninguna parte sino lo llevan los hombres ó los efectos contagiados...

En los párrafos siguientes se dedica a desmontar las teorías de los «anticontagionistas», y especialmente la que sustenta la transmisión de la enfermedad por el aire, lo que le conferiría a la misma un carácter epidémico.

Posteriormente, a propósito de lo dicho por el autor que se cita, nos deja otra interesante observación ${ }^{68}$ :

La proposicion de Auber-Roche, de que el único preservativo de la peste es la civilización, llegará á ser una verdad cuando los esfuerzos de la civilización, uniformando las leyes sanitarias europeas, propendan al desenvolvimiento práctico de todas las grandes cuestiones de higiene pública que forman la felicidad de los pueblos.

La división de criterios sobre el origen del cólera queda patente en el artículo que, curiosamente, va a continuación del de Ramírez, además de estar escrito por un amigo suyo ${ }^{69}$ :

La mayor parte de los que mas han observado y combatido el cólera morbo asiático divide el tratamiento en preservativo y curativo. El primero es bien sabido que se reduce á una higiene bien observada, á la sobriedad y una vida bien arreglada (...) deben evitarse todos los escesos, las bebidas alcohólicas, las sustancias indigestas y la Venus (...), y por fin, evitar el miedo y todas las afecciones morales.

La máxima expresión en España de la mencionada división por el origen de la enfermedad la constituyó el enfrentamiento entre Nicasio Landa, médico oficial de la lucha contra la epidemia y seguidor de las tesis de Pettenkofer, y Méndez Álvaro, contagionista convencido ${ }^{70}$. Y al igual que en el resto de Europa, los descubrimientos de Koch no supusieron un cambio de mentalidad en muchos de nuestros médicos, como lo atestiguan obras posteriores a ellos ${ }^{71}$.

68 RAMíreZ VAS (1854b), p. 561.

69 Benito GonZÁlez, Z. (1854), Cuatro palabras acerca del contagio, infección y tratamiento del cólera morbo, La Crónica de los Hospitales, pp. 566-573.

70 VIÑES, J.J. (2000), El Dr. D. Nicasio Landa, médico oficial en la epidemia de cólera de 1854-1855, Anales del Sistema Sanitario de Navarra, 23 (1), pp. 85-107. Méndez Álvaro desaconsejó la publicación la Memoria sobre el cólera que Landa presentó en 1861 a la Real Academia por sus teorías sobre la influencia del terreno en la difusión de la enfermedad.

71 Ulecia Cardona, J. (1885), Tratamiento del cólera morbo, Madrid. Impr. de la Co- 
Años después Ramírez muestra interés por otra enfermedad infecciosa de sumo interés. Entre 1860 y 1861 publica un extenso trabajo dividido en dos partes de cinco artículos cada una sobre la diátesis tuberculosa. Extraemos un párrafo por lo llamativo de lo expresado en él, posiblemente más producto del deseo que de los conocimientos que se tenían entonces de la enfermedad:

Para destruir la virtud patogenica, ó para producir artificialmente en el organismo una aptitud refractaria á la incubacion y ulteriores evoluciones de los virus; creemos que ha de existir algun medio profilactico especifico (...)

¿Y quién sabe si en un porvenir más ó menos lejano (...) se descubrirán (...) esos preciosos y codiciados preservativos? ${ }^{72}$.

\section{LA CORRIENTE HIGIENISTA}

El cambio de mentalidad ocasionado por las ideas ilustradas del siglo XVIII alcanzó también a la medicina. Las altas tasas de mortalidad que padecían los sectores de población más pobres, junto a sus miserables condiciones de vida, motivó la denuncia de los médicos que estaban en contacto con ellos. La aparición de la obra de Frank La miseria del pueblo, madre de enfermedades suscitó el interés de otros higienistas, reorientando los estudios higiénicos, centrados hasta entonces en la profilaxis de la llamada medicina pública, hacia la desgraciada realidad ${ }^{73}$.

El precursor de la higiene en España fue Ortiz de Landázuri. Pero el verdadero introductor de la disciplina en nuestro país fue Mateo Seoane, liderando, además, una nómina de higienistas que abarcó la práctica totalidad de la centuria, en la que se encontraban sus discípulos Monlau y Méndez Álvaro y que culminarían Giné y Partagás y Rodríguez Méndez.

La corriente higienista que recorría toda la Europa occidental tuvo en España, en el primer tercio del siglo XIX, el obstáculo de la pervivencia del Antiguo Régimen. Superado este escollo, las cosas no mejoraron significati-

rrespondencia de España, p. 38. El autor manifiesta que el origen del cólera «se pierde en un intrincado laberinto».

72 Ramírez VAS, F. (1860a), Diátesis tuberculosa y su profilaxis, Boletín del Instituto Médico Valenciano, 7, pp. 157- 159.

73 AlCAide GonZÁLEZ, R. (1999), La introducción y el desarrollo del higienismo en España durante el siglo XIX. Precursores, continuadores y marco legal de un proyecto científico y social, Scripta Nova. Revista Electrónica de Geografía y Ciencias Sociales, 50, disponible en http://www.ub.edu/geocrit/sn-50.htm (consultado el 9 de marzo de 2011). 
vamente. Los vaivenes políticos, fundamentalmente de la primera mitad de siglo, impidieron la consolidación de esta disciplina. La inestabilidad política, traducida en una cascada de gobiernos de corta duración, cristalizó en sucesivas leyes que intentaron regular tanto los estudios de medicina como el ejercicio de la misma ${ }^{74}$.

A partir de 1843, el estudio de la Higiene se desliga del de la Fisiología. Pero a pesar de haber adquirido carta de naturaleza propia, la importancia de esta disciplina seguirá estando en segundo plano en la Universidad. A excepción de Monlau, en 1854, y tan sólo durante ocho meses, las cátedras de Higiene estuvieron durante muchos años en manos de médicos de paso hacia otras cátedras mejor valoradas ${ }^{75}$.

El papel de los tres higienistas de la etapa burguesa revolucionaria (18351874), Seoane, Monlau y Méndez Álvaro, es fundamentalmente difusor de las teorías británicas, muy influenciadas por las alemanas y también de las francesas. Sus obras carecen de originalidad, propugnando la supeditación de la medicina a la administración pública y el no intervencionismo estatal, tal y como defienden las tesis británicas de los seguidores del filósofo Betham ${ }^{76}$. Hay que señalar que la población objeto de la aplicación de las medidas higiénicas radicaba en las ciudades, quedando las poblaciones rurales fuera de ellas ${ }^{77}$. De igual manera la higiene industrial quedaba al margen de toda intervención ${ }^{78}$.

El interés por la higiene, tanto la pública como en general, se manifiesta en el número de disposiciones legales aparecidas, fundamentalmente, entre 1851 y $1860^{79}$. De la misma manera, el número de publicaciones sobre la materia en este mismo periodo de tiempo es significativo mayor que en idénticos intervalos de tiempo de la misma centuria ${ }^{80}$.

74 Granjel, M. (1983), Pedro Felipe Monlau y la higiene española del siglo XIX, Salamanca, Cátedra de Historia de la Medicina, Universidad de Salamanca, pp. 24-25.

75 GRANJEL (1983), p. 30.

76 AlCAide GoNZÁLEZ (1999).

77 Rodríguez Ocaña, E. y MenÉndez Navarro, A. (2006), La tardía intervención higiénica en el medio rural español: el caso de la lucha contra la anquilostomiasis, 1910-1960, La Mutua (2a época), 16, pp. 71-86.

78 Rodríguez OcAÑA, E. y MenÉndez Navarro, A. (2005), Salud, trabajo y medicina en la España del siglo XIX. La higiene industrial en el contexto antiintervencionista, Archivos de prevención de riesgos laborales, 8 (2). pp. 58-63. Como señalan los autores, «los derechos ciudadanos acababan a las puertas de las fábricas» (p. 62).

79 AlCAide GonZÁlez, R. (1999). En cuanto a la Higiene, entre 1851 y 1860, aparecen 189 disposiciones legales de un total de 343 aparecidas entre 1821 y 1863.

80 GRANJEL (1983), p. 170. 
Francisco Ramírez muestra un temprano interés por la Higiene. De hecho, el primer escrito del que tenemos constancia es sobre esta materia, publicado en el medio en el que más se prodigó en sus inicios, La Crónica de los Hospitales. Es de 1854 y consta de siete artículos ${ }^{81}$ agrupados bajo el título de «Importancia de la higiene considerada en sus relaciones con la ciencia administrativa y moral». No se trata de un trabajo exhaustivo de higiene en todas sus aplicaciones, sino que es más bien una extensa justificación del fomento de la misma en el campo personal, administrativo e incluso moral.

El trabajo en su inicio realiza un largo recorrido por las culturas antiguas, destacando los hábitos higiénicos de estos pueblos, tanto en lo privado como en lo que se refiere al ámbito comunitario.

En la segunda parte, defiende el ejercicio físico y la investigación de las causas de la insalubridad de los pueblos. Critica que el decreto de abril de 1854 no fomente la higiene privada, quedándose sólo en la pública. Como punto sumamente interesante, propone aquí la creación de una asignatura de higiene en la enseñanza primaria.

En la tercera entrega, aborda la salubridad de las viviendas, con especial tratamiento de la ventilación. Arremete contra los especuladores del suelo. Critica la costumbre del medio rural de mezclar personas y animales bajo el mismo techo. La misma opinión le merece la presencia de fábricas en los cascos urbanos. Y una crítica más a las administraciones públicas, más pendientes de la estética de los edificios que de la salubridad de los mismos.

Especialmente interesante nos parece el contenido de la cuarta parte. En él aborda el tema de la beneficencia, expresando que «... si la índole de este artículo nos lo permitiera, descenderíamos a consideraciones de economía política.... ${ }^{82}$. En estas líneas hace votos por un control estatal de los establecimientos destinados a este fin, haciendo incluso nuevas fundaciones y controlando la mendicidad como en algunos departamentos franceses. Aunque generoso de sentimientos, adolece de lo que otros muchos autores: ideas concretas $^{83}$. El siguiente repaso es el de los establecimientos penitenciarios, «... sitios de custodia y no de castigo para los presos...», criticando el mal estado de sus instalaciones y la carencia de grandes patios en los que poder realizar ejercicio los confinados.

81 RAMíRez VAS, F. (1854c), Importancia de la higiene considerada en sus relaciones con la ciencia administrativa y moral, La Crónica de los Hospitales, pp. 232-238, 300-306, 328335, 357-367, 392-401, 483-494, 649-655.

82 RAMíREZ VAS (1854c), p. 359.

83 Marsal I Ferret, M. (2002), Pobreza y beneficencia pública en el siglo XIX español, Valladolid, Lex Nova, pp. 53-56. 
En la quinta, defiende la hospitalidad domiciliaria, alegando que «... los grandes hospitales son focos de infección difícil de remover...». Sigue con una propuesta de mejora en la atención a los niños expósitos, siendo atendidos en casa de la nodriza e incentivando la buena atención de éstas.

En el penúltimo capítulo trata el problema de la insalubridad de las charcas y de los cultivos acuáticos, defendiendo «la combatida idea del contagio».

Finaliza el trabajo abogando en su última parte por el aseo personal y el baño, estimando en cuarenta litros de agua las necesidades diarias de cada individuo.

El 18 de febrero de ese año de 1854, había pronunciado un discurso en la Academia del Cuerpo de Sanidad Militar del distrito de Extremadura, que tituló «Importancia de la higiene y necesidad de generalizar sus preceptos en el Ejército». De corte similar al trabajo anterior, del que es prácticamente coetáneo, se centra más en aspectos propios del ejército, como corresponde al caso. Dedica buen espacio a ensalzar los beneficios del ejercicio físico y a combatir la ociosidad del soldado. Entra, posteriormente, a valorar lo que debe ser una buena alimentación, considerando que deben recortarse las verduras e incrementar el consumo de carnes y pescados. Considera la práctica de la natación una buena medida, tanto higiénica como deportiva. Finalmente, habla de la instauración de una Cartilla Militar de Higiene, donde se recogerán diversos consejos para una vida saludable del soldado.

En 1855 entra a formar parte de la Sociedade da Sciencias Medicas de Lisboa y publica la memoria de ingreso en el Boletín de esta Academia portuguesa. En 1859 comenzó la publicación del anterior trabajo en el periódico barcelonés La Alianza Médica, sin finalizar la misma en este medio impreso. Esteban Quet, entonces director de dicho periódico, se comprometió con Ramírez a publicar íntegra dicha memoria en la publicación de la que se hace cargo en 1860: La España Médica. Y en sus páginas vio por fin la luz este trabajo, que no se diferencia en nada de los referidos anteriormente ${ }^{84}$.

\section{HIGIENE Y ESCUELA: UN INTENTO FALLIDO}

Ramírez apuntaba, como acabamos de ver, en uno de sus trabajos, la necesidad de convertir esta disciplina en materia de estudio en la escuela, como primer escalón para acogerse a hábitos saludables. De tal manera, y siguiendo

84 RAmíRez VAS, F. (1860b), Importancia de la higiene y necesidad de generalizar sus preceptos, La España Médica, pp. 66-71, 88-91, 103-106. 
la costumbre de poner en práctica lo que pensaba, se embarcó en una segunda aventura editorial, publicando su Compendio de higiene o arte de conservar la salud, título de resonancias conocidas de publicaciones de otros higienistas contemporáneos. La obra — «opúsculo» lo llama su autor- va destinada a convertirse en texto escolar, cosa que no fue posible. Veamos la estructura del trabajo en cuestión:

Introducción.

Parte 1. a. Influencias dependientes del individuo.

Cap. $1 .^{\circ}$. De las influencias climatológicas.

Art. $12^{\circ}$. De la composición y pesantez del aire.

Art. $22^{\circ}$. De los vientos.

Art. $3 .^{\circ}$. De la alteración del aire.

Art. $4 .^{\circ}$. De la temperatura atmosférica. Climas.

Art. $50^{\circ}$. De la electricidad atmosférica.

Art. $69^{\circ}$. De la luz.

Art. $7 .^{\circ}$. De los sonidos.

Art. $8 .^{\circ}$. De las habitaciones.

Cap. $2 .^{\circ}$. De las influencias cosmetológicas.

Art. $1 .^{\circ}$. De los vestidos.

Art. $22^{\circ}$. De la limpieza del cuerpo.

Cap. $3 .^{\circ}$. De las influencias alimenticias.

Art. $12^{\circ}$. De los alimentos.

Art. $2 .^{\circ}$. De las bebidas.

Parte 2. ${ }^{\text {a }}$ Influencias propias del hombre sobre sí mismo.

Cap. $1 .{ }^{\circ}$. De las influencias sensitivas y afectivas.

Art $^{\circ} .1{ }^{\circ}$. De las sensaciones y pasiones.

$\mathrm{Art}^{\circ}$. $2{ }^{\circ}$. De las facultades intelectuales.

$\mathrm{Art}^{\circ} .33^{\circ}$. Del trabajo intelectual.

Cap. 2. ${ }^{\circ}$. De las influencias gimnásticas.

Art $^{\circ} .1{ }^{\circ}$. Del ejercicio.

Art $^{\circ}$. 2. ${ }^{\circ}$. Del reposo.

Cap. $33^{\circ}$. De las influencias orgánicas.

$\mathrm{Art}^{\circ}$. único. De las constituciones.

Cap. $4 .^{\circ}$. De las influencias adquiridas.

Art $^{\circ}$. único. Del hábito.

Conclusión 
La obra fue escrita en 1852, según figura en el manuscrito, siendo remitida para su aprobación como texto escolar. La respuesta del Real Consejo de Instrucción Pública fue negativa, «porque debiera reducirse á reglas y preceptos propios para niños, suprimiendo lo que conviene que estos ignoren, y redactándola en términos adecuados á su comprensión $\rangle^{85}$. Viendo el índice parece justificada la anterior negativa, en la época de su redacción, y leyendo someramente el texto, se comprende que no fuera excesivamente inteligible para niños. No obstante, se añade adelante, se considera que:

(...) atendiendo al mérito de la obra, la Reina (q. D. g.) se ha servido resolver que se recomiende su estudio á los Profesores de toda clase y á las corporaciones, siempre que V. la imprima y presente dos ejemplares.

Finalmente, el trabajo, como se le pedía, se imprimió en 1858, aunque no tenemos constancia del destino real que se le dio. Lo cierto es que sí hubo médicos de cierto renombre, como Esteban Quet y Mariano Benavente, que manifestaron, como veremos, su interés por la obrita.

Como es sabido, en 1860 Monlau sacaba a la luz su obra Nociones de higiene doméstica y gobierno de la casa, destinada por Real Orden a ser texto de las escuelas ${ }^{86}$, eso sí, sólo de señoritas, ajustándose de esta manera al Artículo 5. ${ }^{\circ}$ de la conocida «Ley Moyano» de 1857 . Con similar objetivo aparecería en 1863 otra obra menos conocida, pero también destinada a texto de escuela, del higienista leonés Díez Canseco ${ }^{87}$.

\section{OTRAS CUESTIONES DE INTERÉS}

Dentro del debate surgido en torno a la nueva legislación deseada por los médicos españoles, y que abocaría en la Ley de Sanidad de noviembre de 1855, surgieron diversas propuestas. El Estandarte Médico surgió fundamentalmente como medio de expresión de Ramírez en este tema. En sus páginas encontramos un extenso análisis del estado de la cuestión por parte de su director y de otros profesionales, en el que no faltan propuestas. En el tercer número del periódico, encontramos un interesante artículo sobre el proyecto

85 La resolución del Real Consejo lleva fecha de 18 de diciembre de 1852.

86 GRANJEL (1983), p. 145.

87 Díez Canseco, V. (1863), Catecismo higiénico para los niños, León, Establecimiento tipográfico de Miñón. 
de Asociación Médica, al final del cual Ramírez lanza la idea de la obligatoriedad de realizar una memoria anual en los siguientes términos ${ }^{88}$ :

$1^{\circ}$ Tanto el médico como el cirujano al finalizar el año darían una memoria de las enfermedades que hubiesen predominado; si eran endémicas, epidémicas ó contagiosas; qué causas habían determinado su manifestación; si eran accidentales ó permanentes, y qué medidas habían de adoptarse para extinguir los focos de insalubridad y mejorar las condiciones higiénicas de la población. También acompañarían un estado de los muertos y su proporción con los curados, especificando los métodos curativos empleados. De esta manera se reunirían preciosos materiales para la estadística y para la geografía médica de España. $2^{\circ}$ Los farmacéuticos igualmente darían una noticia de las plantas y aguas medicinales para contribuir á perfeccionar la flora española y la hidrología médica.

En el anterior párrafo, Ramírez expresa su convicción de la utilidad de la estadística, cuestión por la que mostrará interés también Méndez Álvaro, no así su admirado Monlau. En el último número del periódico, vuelve a esta idea, en oposición a la proposición de Broussais, quien afirmaba «que no es posible hacer salir de un número otra cosa que un número» ${ }^{89}$. Propone además la asociación de la anatomía patológica y del análisis estadístico para que el diagnóstico sea más fiable.

En el cuarto número destacamos una interesante reflexión sobre la Beneficencia. Ramírez reclama el derecho de los menesterosos a una caridad pública y la obligación del Gobierno de proteger los asilos piadosos. Ejemplariza la lamentable situación de la Beneficencia en dos casos, el de una señora anónima y el de un ministro, que han contribuido con dinero propio y mantas a sostener el Hospital de Beneficencia de Madrid. La Ley General de Beneficencia de 1849 y el posterior Real Decreto de 1852, aprobado para la ejecución de dicha Ley, creaba las Juntas Provinciales de Beneficencia, estableciendo así el control del Estado sobre los establecimientos de caridad. La Ley de Sanidad de 1855 deja en manos de las Diputaciones provinciales el control de la Beneficencia. En su Artículo 64 se refiere a la Beneficencia domiciliaria de esta manera: «las Juntas Provinciales de Sanidad invitarán a los Ayuntamientos a que establezcan la hospitalidad domiciliaria», evidenciando la falta de un modelo obligatorio a seguir por parte de las entidades locales ${ }^{90}$. Esto

88 RamíRez VAS, F. (1855d), Examen crítico del Proyecto de Asociación Médica, El Estandarte Médico, pp. 36-37.

89 RAMírez VAS, F. (1855e), Importancia de la estadística, El Estandarte Médico, p. 133.

90 BARONA VILAR, C. (2006), Las políticas de la salud. La sanidad valenciana entre 1855 y 1936, Valencia, Publicaciones de la Universidad de Valencia. 
dará lugar a la falta de un control efectivo de las Diputaciones, especialmente, sobre los establecimientos de beneficencia privados ${ }^{91}$, cuya situación se vería agravada por las sucesivas desamortizaciones que sufrieron estas entidades.

De nuevo en las páginas de El Estandarte Médico, en su octavo número, en un artículo que firma Ramírez se aboga por la especialización en pediatría, con centros específicos para niños ${ }^{92}$. Aunque los primeros tratados sobre pediatría en España hay que buscarlos dos siglos antes ${ }^{93}$, los programas de enseñanza tardaron en reflejar la nueva tendencia. La primera cátedra de pediatría en España data de 1887 y el primer hospital pediátrico, el Niño Jesús, de Madrid, es de 1876. Todavía en el congreso de la Sociedad Ginecológica Española que tuvo lugar en 1910, se trataron temas de pediatría.

Ramírez publica otros trabajos sobre temas terapéuticos, eligiendo para ello el Boletín del Instituto Médico Valenciano: hernias estranguladas (publicado en 1859), gastralgias (1863) o viruela (1873). Entre 1858 y 1877 publica en este Boletín diversos artículos, siempre de carácter científico. A excepción del último ${ }^{94}$, en el que hace alguna puntualización — bastante irrelevante, por cierto- a Juan Bautista Peset a propósito de un trabajo de éste sobre la historia de la medicina valenciana. Anécdotas aparte, sorprende que en este medio escrito Ramírez no toque uno de sus temas favoritos, como es el de la higiene.

Los trabajos realizados en los últimos años, sobre todo en 1877, los dedica a un hecho sorprendente: la curación súbita de una mujer de la localidad pacense de Villafranca de los Barros en 1874, que había quedado ciega diez meses antes. La paciente fue estudiada desde el inicio por un pionero de la

91 Entre 1870 y 1874 la Inspección de Beneficencia de Badajoz, solicita reiteradamente determinados documentos a la Santa Casa de Misericordia. Entre otros temas, se pregunta por la falta de renovación de los cargos de la Mesa que dirige dicho establecimiento. La falta de respuesta alguna por parte de la Mesa dará lugar a la intervención del Gobernador Civil de la provincia en 1870 (AHMO, 5/22). En 1874, ante la falta de colaboración de la institución benéfica, el Gobernador procede a dar un ultimátum a la Mesa (AHMO, 5/49), ordenando la inspección de las cuentas del establecimiento, bajo la sospecha de una mala gestión, cosa que tampoco se pudo llevar a cabo.

92 RAmírez VAS, F. (1855f), Necesidad de dar más amplitud al estudio teórico y práctico de las enfermedades de la infancia, El Estandarte Médico, p. 113.

93 ARANA AMURRIO, J.I. (2000), Evolución de los saberes pediátricos en España desde el tratado de Gerónimo Soriano. Cuatro siglos de historia, Conferencia inaugural del Congreso de la AEP de 2000. Disponible en: http://scptfe.com/microsites/Congreso_AEP_2000/Ponencias-htm/ conferencia_inaugural.htm (Consultado el 14 de abril de 2011).

94 RaMírez VAS, F. (1877a), Una duda, Boletín del Instituto Médico Valenciano, 15, pp. 220-224. 
oftalmología española: el doctor Chiralt ${ }^{95}$. Tras la súbita curación de la ciega, el Obispado de Badajoz ${ }^{96}$ encargó una investigación a la recién creada Academia de Ciencias Médicas de Badajoz, concluyendo la Comisión creada al efecto que no había explicación científica al hecho. La no aceptación del dictamen por una parte de los académicos originará un debate interno y externo que tendrá su principal repercusión en el relevo de Benito Crespo como presidente de la Academia. Era el colofón a una lucha que tuvo su reflejo en las páginas, fundamentalmente, de La Correspondencia Médica, que se hizo eco de la teoría del principal opositor de Ramírez, Narciso Vázquez ${ }^{97}$. No parece que Ramírez tuviera igual trato por parte de esta publicación, pues a pesar de los contactos mantenidos con el director de la publicación, Juan Cuesta Ckerner ${ }^{98}$, el periódico, a través del administrador, da por zanjado el tema en agosto de $1877^{99}$. Todo lo acontecido queda recogido en una obra que finalmente

95 Según consta en el expediente de investigación del Obispado (ARV, 8/29), Chiralt etiquetó el padecimiento de «neuritis óptica bilateral». La afección, según se relata en él, siguió evolucionando hasta la pérdida, prácticamente total, de la visión.

96 El Obispado interviene en el asunto por en hecho de haberse producido la supuesta curación cuando un paso de Semana Santa transitaba ante la ciega, por lo que los testigos etiquetan el hecho como milagroso.

97 Narciso Vázquez Lemus fue uno de los miembros fundadores de la Academia pacense. Destacó tanto o más en su faceta político-social que en la médica. «Republicano uterino», como le llamó Miguel Maura, masón y «no creyente», vería colmadas sus aspiraciones cuando en 1934, por razón de edad, presidió las Cortes Constituyentes de la Segunda República (ENRÍQUEZ Anselmo, J. (1995), El Dr. Augusto Vázquez. Su tiempo y circunstancias sociopolíticas, Cáceres, Servicio de Publicaciones, Universidad de Extremadura, p. 22). La teoría de Vázquez es que la ceguera en cuestión obedece a una contracción temporal del «anillo» de Zinn (así denomina al ligamento de Zinn), algo más que improbable como ya entonces apuntara Ramírez, bien asesorado por otro pionero de la oftalmología: Luis Oliveres. Ramírez, al igual que Chiralt, Oliveres, Crespo o Regino de Miguel, no encuentran explicación al caso. Si bien creen que la alteración que originó la ceguera pudo ser una neuritis óptica o, con menor probabilidad, una «fluxión hiperhémica crónica», no encuentran razón para una curación súbita. Éste es el motivo por el que Ramírez, en el discurso inaugural del periodo de sesiones de la Academia de Ciencias Médicas de Badajoz, en 1877, expresa, parafraseando a un colega: «donde acaba la ciencia principia la duda, y yo añado: donde acaba la duda principia la fe». Sin embargo, en contra de lo que pueda parecer, siempre se abstuvo de hablar de un posible milagro.

98 Existen diversos borradores de cartas y artículos remitidos a la redacción de este periódico referentes al asunto de la ciega. ARV, 8/11-15.

99 ARV, 8/16. 
no vería la luz ${ }^{100}$, aunque sí nos dejaría impreso el discurso que sobre el tema pronunció en la Academia pacense en $1877^{101}$.

\section{LA CORRESPONDENCIA}

Tanto la aparición de El Estandarte Médico como la publicación de sucesivos trabajos en prensa por parte de Ramírez generaron una abundante correspondencia con numerosos médicos. La pervivencia de estas cartas constituye un valioso testimonio de la actualidad médica, política y social del periodo que abarcan ${ }^{102}$. Con respecto a la aparición del periódico oliventino, se conservan numerosas suscripciones de médicos, fundamentalmente de la provincia de Badajoz. Visto el cariz de los escritos de Ramírez a propósito de la situación que vive tanto la medicina como los médicos, algunos suscriptores se dirigen a él para dar su opinión o para contar su caso concreto. Sobre lo primero, la carta de Zacarías Benito ${ }^{103}$ ilustra el pesimismo reinante entre los médicos en ese momento ${ }^{104}$ :

Esto está cada vez en peor estado con haberse dividido en partidos, y aun cuando nosotros en nada nos mezclamos, nos alcanzan algunos de los efectos faltándonos, hasta el más inferior, á las consideraciones que debieran tenernos: sobre todo es intolerable la exigencia de que nadie ha de morirse (...) mi compañero ha sido hasta insultado, y á mí se me ha faltado: nos hemos quejado á la autoridad, y está

100 ARV, leg. VIII, carpeta 1. Con el título de La ciega de Villafranca. Estudio médico de su enfermedad: su curación instantánea y prodigiosa. Contaba incluso con la censura eclesiástica. Era, por tanto, el texto para entregar a imprenta. Es más que probable que la impresión no se llevara a cabo por motivos de salud del autor.

101 RAMíReZ VAS, F. (1877b), Sobre la curación súbita y espontánea de la ceguera de Felisa Sánchez, Badajoz, Imprenta de José Santamaría.

102 SÁnchez Álvarez, J.L. y Peral Pacheco, D. (2005), La correspondencia del doctor Francisco Ramírez Vas (1818-1880). Una breve reseña, Revista de Estudios Extremeños, LXI (1), pp. 189-204. Diputación de Badajoz, Servicio de Publicaciones, P. 189-204. En este somero trabajo se ha agrupado la correspondencia en función de la ocupación del remitente. Encontramos entre los remitentes políticos, escritores, editores, impresores, familiares, y, sobre todo, médicos; siendo, por tanto, una excelente fuente de información de aquella época.

103 De este médico se sabe poco. Estuvo de médico en Corral de Almaguer. En 1861 era director del Hospital de dementes de Toledo. En FERnÁNDEZ-TorRes, B, MÁrqueZ-EsPinós, C. y Mulas BÉJAR, M. de las (2001), Controversias en torno al dolor y la anestesia inhalatoria en la España del siglo XIX, Revista Española de Anestesiología y Reanimación, 48, p. 237.

104 ARV. 13/134. Carta de 18 de mayo de 1855. 
pronta á protegernos; pero qué medida tomar contra hombres de tu partido, cuando las mas noches andan á trabucazos?. Por manera que el compañero se despide y se va á Valencia, adonde tiene casa, y yo lo haré tan luego encuentre colocación.

Otro ejemplo que retrata la situación límite que vivían los médicos, particularmente en poblaciones rurales, donde de forma más intensa se hacía notar el despotismo de las autoridades locales, lo encontramos en la misiva de José Sánchez, médico de Alcántara. En ella solicita la anulación de la suscripción a El Estandarte Médico «por persecución de estos caciques», como refiere literalmente ${ }^{105}$.

El periódico de Ramírez y sus opiniones vertidas en él le acarrearon una cierta fama entre el mundo periodístico. Nada más cerrar sus páginas, su director comenzó a recibir ofrecimientos de otros periódicos para que escribiera en ellos, como El Iris de la Medicina ${ }^{106}$ y El Porvenir Médico ${ }^{107}$. Con respecto al cierre del periódico, un comentario de Zacarías Benito viene, veladamente, a reforzar las críticas que Ramírez hizo a la dirección de El Siglo Médico $^{108}$ :

Siento en el alma que su apreciable periódico no haya podido sostenerse, por que, á lo que he visto, amen de la excelente parte doctrinal, las clases médicas tenían un buen defensor de sus intereses, con mucha mas razon que otros de igual modo que solo atienden á los suyos propios; pero la suerte de los periódicos de provincia, está ya bien regulada por la posición de los profesores en general. Hay algunos tiburones en la Corte que todo lo absorven; y no puede menos de ser así, porque los facultativos de partido no pueden inscribirse á todos los periódicos útiles, por grande que sea su entusiasmo, á causa de su precaria situación. Pero á bien que ahora las Cortes y diputados médicos lo arreglarán...

La mayoría de las cartas que se conservan de los diversos directores de revistas y periódicos médicos hablan de la publicación de diversos trabajos de Ramírez, y del interés despertado por el autor, como señala Félix Borrel, de El Pabellón Médico ${ }^{109}$ :

105 ARV, 13/60. Carta fechada el 18 de marzo de 1855.

106 ARV. 3/70. Carta de la dirección, de fecha 13 de abril de 1855 ofreciéndole a Ramírez sus páginas para publicar.

107 ARV. 13/71. Carta del director, Enrique Méndez, de 24 de abril de 1855, en similares términos que la anterior. El ofrecimiento lo reitera el nuevo director, nombrado poco después, Marcial de Reyna, mediante carta de 21 de mayo siguiente (ARV, 13/113).

108 ARV. 13/66. La carta es de 27 de marzo de 1855.

109 ARV. 13/ 37. Carta de 28 de diciembre de 1861. 
Muy Sr. mío y estimado comprofesor: habiendo observado hace muchos años que es Vd. colaborador tan laborioso como ilustrado de varios periódicos de Medicina que se publican en España, aprovecho la ocasión de tenerle que dar á Vd. las gracias por haberse dignado suscribirse á el "Pabellón", para ofrecerle las columnas del mismo, en la seguridad de que se dignara $\mathrm{Vd}$. honrarlas con sus escritos éstos aparecerán en lugar preferente y se procurarán que aparezcan con toda la corección tipográfica que mi periódico tiene acreditada.

En similar sentido se pronunciarán otros, como José Benito Benavides ( $L a$ Crónica de los Hospitales), Rafael Ulecia (Revista de Medicina y Cirugía prácticas, nacional y extranjeras), Sánchez Rubio (La España Médica), Esteban Quet (La Alianza Médica), Francisco de Paula Alafont (Boletín del Instituto Médico Valenciano), además de los mencionados Reyna y Méndez.

Caso aparte es el de Méndez Álvaro, director de El Siglo Médico. El primer contacto de Ramírez con el director de El Siglo Médico, el periódico de mayor prestigio y que mejores plumas contaba entre sus filas, fue a propósito del nacimiento del rotativo de Olivenza. Ya las cosas comenzaron como luego continuarían: con un permanente desencuentro entre los dos directores. Ramírez envió, como a otros periódicos, el prospecto del suyo, que no fue publicado por El Siglo Médico. Hecho que provocaría la crítica de Ramírez a la dirección del periódico madrileño, críticas que se repetirían desde las páginas de El Estandarte. La que posiblemente es la primera carta de Méndez Álvaro a Ramírez viene motivada por esas críticas vertidas en el periódico pacense. En ella se excusa por no haber publicado el referido prospecto, debido a que no lo recibieron en la redacción de su periódico ${ }^{110}$.

Ya en el terreno científico, también se conservan diversas cartas en las que el remitente valora lo publicado por Ramírez. De una de las cartas de Benavides, a propósito de estos trabajos, extraemos unas líneas referentes a la contagiosidad del cólera ${ }^{111}$ :

Mui Sr mio y mi estimado colaborador: Con mucho placer he recivido sus atentas de V una en Valencia y otra hallándome de vuelta en Madrid.

Con la primera recibí un verdadero testimonio de su deferencia, laboriosidad é interés por los adelantos de la ciencia y con la segunda, después de repetir los ofrecimientos que en aquella, su artículo dedicado á provar la contagiosidad del Cólera morbo asiático. Tanto por lo uno como por lo otro debo manifestarle mi eterna gratitud y la de esta redacción, advirtiéndole al mismo tiempo que esta ha recivido un

$110 \mathrm{ARV}, 3 / 89$. La carta no tiene fecha pero, por el tema tratado, podemos ubicarla en los primeros meses de 1855 .

111 ARV. 13/65. Carta de 4 de octubre de 1854. 
obsequio considerandole como uno de sus colaboradores. Yo por mi parte estoy tan de acuerdo con las ideas emitidas por $\mathrm{V}$. en su ultimo artículo relativamente al contagio que si algún día mi ocupación me lo permite pienso tratar con alguna estensión el mismo asunto y en el mismo sentido que V. lo hace, aunque acaso, no con tanto tino como requiere materia tan delicada.

\section{Sobre sus trabajos de higiene mostró especial interés Estaban Quet:}

Hay reparaciones tardías, pero que entre personas generosas siempre, o en todas ocasiones, se aprecian.

Cuando en Barcelona publicaba La Alianza Médica, merecí de V el favor de las Memorias sobre la Importancia de la higiene y necesidad de generalizar sus preceptos, la q, como V. sabe, empecé á insertar en dicho periódico, publicando su mayor parte (...) y con mi traslado á esta corte me quedé en Barcelona el final de dichas Memorias, sin que acertase nunca á remitírselo, por cuyo unico motivo no acabé de darle á luz (...) á la muerte definitiva de dicha Alianza.(...). Ahora obra en mi poder la conclusión de la misma, y mi objeto (...) es indicarle o saber si tiene el inconveniente en q se reproduzca entera en la España Médica, ya que escribe V. también en ella, pues es verdaderamente lástima q dicho trabajo, rico en preciosos datos y bellas ideas no alcance la mayor publicidad posible."112

Igualmente, su pequeño compendio de higiene suscitó interés entre algunos de los personajes mencionados más atrás, como Quet. Mariano Benavente es más expresivo al respecto ${ }^{113}$ :

Mi estimado amigo: adjunto remito á V. un cristal de vacuna fresca, estraída hoy mismo de los granos de un niño robusto, y que juzgo preferible á la inglesa por que dá generalmente resultados mas seguros que esta. Nada me ha costado el obtenerla, por que entre sastres no se pagan hechuras; y por lo tanto puede V. indicarme el destino que he de dar á las diez v. q tengo en mi poder. Su Compendio de Higiene me gusta como todo lo que V. escribe, y me parece que si le hubiera V. dado alguna mas estensión, pudiera haber cogido algún fruto destinándolo á los alumnos de las facultades de Medicina, los cuales lo hubieran comprado por ahorrarse el trabajo de leer obras más estensas. De todos modos siento que haya V. sufrido el percance de no haber sido atendido por el Gobierno (lo cual es bastante común, por desgracia, en esta tierra de garbanzos) (...). De seguro hubiera V. vendido una ó dos ediciones de su compendio, si se hubiera publicado en Paris y se llamara V. Mr. Vas!...

112 ARV. 13/35. Carta de 22 de enero de 1859. En 1860 publicaría en el mismo periódico Importancia y necesidad de la Estadística, La España Médica, p. 405.

113 ARV, 13/67 b. Carta de 13 de marzo de 1863. 
En otro orden de cosas, la correspondencia mantenida con Monlau tiene mucho que ver con la pertenencia de éste al Real Consejo de Sanidad. Él es el que informa a Ramírez de la futura concesión de una de las condecoraciones que, como vimos, le fueron otorgadas; y de paso, nos muestra la faceta más ambiciosa del médico afincado en Olivenza ${ }^{114}$ :

(...) ayer se acordó proponer á V para la Cruz de Carlos $3^{\circ}$, que es cruz de más categoría que la de Isabel la Católica, que V. deseaba.

En otra de ellas, amén de otros detalles, nos habla de la futura visita al Lazareto de Mahón ${ }^{115}$ :

(...) hace tres días llegué de Panticosa (...) y me encontré con la favorecida de V. del 5 pidiéndome nuevamente vacunas. Sin embargo, difícil hubiera sido servirle á V., porque no sé de donde sacarla, á pesar de todas mis gestiones. De Valencia, la Comisión del Instituto se me negó rotundamente á remitir vacuna durante la canícula; y ahora que me prometía encontrarla muy pronto, recibí ayer la órden de pasar á inspeccionar el Lazareto de Mahon, viaje que emprendo mañana, por la vía de Alicante.

Sin embargo, a pesar de la manifiesta y pública admiración que Ramírez sentía por Monlau, no hay constancia alguna del más mínimo intercambio de pareceres sobre Higiene. Otro tanto ocurre con la Pediatría: ningún comentario entre Ramírez y Ulecia o Benavente, pioneros de esta disciplina en España ${ }^{116}$.

Finalmente, leemos la opinión de Aureliano Maestre de San Juan sobre su buen amigo y condiscípulo Ramírez ${ }^{117}$ :

He leido diferentes artículos en los periódicos médicos debidos á tu buena pluma que me han gustado mucho y corroborado la buena idea que siempre tuve de tus talentos.

Tengo el gusto de remitirte el ejemplar que deseas el cual espero aceptes en testimonio de nuestra antigua amistad; así mismo también te envío adjunto un ejemplar de una memoria q escribí el año pasado sobre el cloroformo y q recorda-

114 ARV, 13/ 121. Carta de 27 de noviembre de 1855.

115 ARV, leg. XI, carpeta 7 c. Carta de 29 de agosto de 1858.

116 Encontramos la misma circunstancia en torno a la literatura, que constituía su segunda actividad. En todas las cartas que remite Adelardo López de Ayala, dramaturgo de gran éxito en vida y varias veces ministro liberal, no hay referencia alguna a temas literarios, tan sólo interesa la política.

117 ARV, 11/ 9 a. La carta, remitida desde Granada, es de 2 de enero de 1861. 
rás dio motivo á varios debates en la prensa, y cuyo trat ${ }^{\circ}$ deseo utilices en tu practica y espongas tu opinión acerca de él.

Otra carta de Maestre de San Juan cierra este recorrido por la correspondencia de Ramírez. El relato que en ella nos hace de su periplo por parte de Europa, aun sin detallar nada en concreto, pone de manifiesto el escalón que separa a nuestra medicina de la de los países que visita, a la vez que señala el camino que su autor está emprendiendo en pos de la Histología española ${ }^{118}$ :

En efecto llevé a cabo este último verano una escursión científica cuya marcha fue de Madrid a Zaragoza Barcelona, Gerona, Figueras, Perpignan, Nimes, Narbona, Cette Nouvelle, Montpellier, Marsella, Lyon, París, Amiens, Londres, Tours, Burdeos; y me vine por Irun, San Sebastián, Pasages, Vitoria, Burgos, Valladolid, Ávila, a Madrid y después á ésta tu casa.

Visité todos los hospitales civiles y militares de todas estas poblaciones, especialmente en Montpellier, su escuela, en Lyon su escuela a la que me acompañó el Dr. Petrequin, y en París en donde asistí a las lecciones de los Profs. en la Facultad, vi todos los hospitales, serví de ayudante en operaciones a Maisonneuve, Velpeau, Jober, Depaul, etc., estube en Charenton Bicetre La Salpetriere, etc y estudié detenidamente los preciosos museos de Orfila y Dupuytren en donde admiré las preparaciones de Sapey, Robin, Bourgnon etc.

En Londres admiré sus verdaderas maravillas, y visité la escuela y su famoso museo de Hunter, así como los hospitales de Gay, Brompton, S. Jorje, S. Bartolomé, Chelsea, este y sus preciosos museos anats. del mismo modo que varios mus. anats. particulares, y la famosa casa de orates de Bedlam etc., etc, deteniéndome en esta inmensa ciudad especialmente en ver las colecciones micrográficas etc.

Sería el nunca acabar si te escribiera todo lo que he visto. Tengo proyectado otro viaje para dentro de un par de veranos á Bélgica, Holanda, Prusia, Austria y Rusia, y si puedo disponer de bastante tiempo también a Italia.

Supongo asistirás al congreso médico de Madrid y remitirás también algunos trabajos; por mi parte haré todos los esfuerzos por concurrir, veremos si estas asociaciones se aclimatan en España como lo están en el estranjero.

\section{CONCLUSIONES}

El recorrido por las publicaciones de Francisco Ramírez Vas nos permite hacer básicamente dos apreciaciones. De un lado, el posicionamiento beligerante del autor en cuestiones profesionales; de otro, su escasa originalidad en los temas científicos. Esto último, quizá, era mal común, no ya en la prensa

118 ARV, 11/ 9 b. Carta de 14 de febrero de 1863. 
española, sino en nuestra medicina. Lo que no le resta mérito en su papel de propagador de las teorías que pensaba más acertadas, bien fuera sobre higiene, sobre la contagiosidad del cólera, sobre la utilidad de la estadística o sobre los demás temas analizados.

En la progresiva actualización de nuestros médicos tiene mucho que ver la difusión de los medios escritos, entre los que destaca la prensa médica. A mediados del XIX, el periodismo médico adquiere además un papel reivindicativo de los intereses profesionales médicos, justificando la aparición de periódicos en pequeñas localidades de la periferia geográfica. Éste es el caso de El Estandarte Médico, púlpito de voces discordantes en lo profesional y mero difusor de cuestiones científicas planteadas en otros medios.

La correspondencia surgida a la sombra de los diversos artículos que publica Ramírez suponen un excelente complemento informativo de las cuestiones que se tratan en algunos de ellos. Tienen, además, el valor añadido de reflejar ciertos aspectos de la realidad de la medicina española y de algunos de sus nombres.

A nivel profesional, el mayor mérito de Francisco Ramírez, por fortuna para sus pacientes, fue llevar a su práctica diaria las tesis que defendió en sus trabajos, haciendo buena la expresión de Sigerist ${ }^{119}$ :

No son ciertamente los grandes médicos los que determinan el estado sanitario de una población, sino el ejército de los médicos prácticos que, dispersos por todo el país, se hallan al lado del enfermo.

Recibido: 5 de octubre de 2007.

Aceptado: 24 de octubre de 2009 .

119 Sigerist, H.E. (1919), Grosse Ärtze, Barcelona, Ediciones AVE, p. 8. Traducción de Francisco Arasa y Manuel Scholz en 1949. 